\title{
Highly conserved hemagglutinin peptides of H1N1 influenza virus elicit immune response
}

\author{
Neha Lohia ${ }^{1,2} \cdot$ Manoj Baranwal $^{1}$ (D) \\ Received: 12 November 2017 / Accepted: 9 November 2018 / Published online: 20 November 2018 \\ (c) Springer-Verlag GmbH Germany, part of Springer Nature 2018
}

\begin{abstract}
In the current study, two highly conserved (>90\%) H1N1 hemagglutinin peptides STDTVDTVLEKNVTVTHSVNL (H1) and KVNSVIEKMNTQFTAVGKEF (H2) containing multiple T-cell epitopes have been assessed for their immunogenic potential in vitro, subjecting peripheral blood mononuclear cells from healthy volunteers to repetitive stimulation of chemically synthesised $\mathrm{H} 1$ and $\mathrm{H} 2$ peptides, and measuring their interferon (IFN)- $\gamma$ level (ELISA) and proliferation (MTT assay). Further, these peptides were analysed for their binding affinity with 18 different human leukocyte antigen (HLA) class I and II by means of molecular docking. All seven samples tested for H1- and H2-induced IFN- $\gamma$ secretion were found to have enhanced IFN- $\gamma$ production. Six (H1) and five (H2) samples have shown proliferative response compared to unstimulated cells. Peptide-induced IFN- $\gamma$ secretion and proliferation in healthy samples represent the immunogenic potential of these peptides. Further, molecular docking results reveal that the peptides have comparable binding energy to that of native bound peptide for both HLA classes which indicates that these peptides have the capability to be presented by different HLA molecules required for T-cell response. Hence, these conserved immunogenic hemagglutinin peptides are potential candidates for influenza vaccine development.
\end{abstract}

Keywords Influenza virus $\cdot$ T-cell-based vaccine $\cdot$ Lymphocytes $\cdot$ Interferon $\cdot$ Molecular docking $\cdot$ Peptides

\section{Introduction}

Influenza is a common human respiratory infection with an estimated annual occurrence rate of $5-10 \%$ in adults and $20-30 \%$ in children, globally (WHO 2014). Out of the three influenza virus, influenza A virus is of utmost health concern worldwide. Most recent pandemic outbreak caused by influenza A (H1N1)pdm09 resulted from the emergence of a novel influenza virus having neuraminidase (NA) and matrix (M) genes from 'Eurasian swine' influenza lineage and the rest of genes from triple reassortant swine influenza

Electronic supplementary material The online version of this article (https://doi.org/10.1007/s13205-018-1509-3) contains supplementary material, which is available to authorized users.

Manoj Baranwal

manoj.baranwal@thapar.edu

1 Department of Biotechnology, Thapar Institute of Engineering and Technology, 147004 Patiala, India

2 School of Life Sciences, Jaipur National University, Jaipur, India virus of avian, human and swine influenza virus (Galiano et al. 2011). Presently, influenza A virus subtypes H1N1 and $\mathrm{H} 3 \mathrm{~N} 2$ are circulating in humans and are capable of sustaining human-to-human transmission.

The immune response generated soon after the onset of natural influenza infection is governed by antibodies directed against surface glycoprotein hemagglutinin (HA) and NA. $\operatorname{IgA}, \mathrm{IgM}$ and $\mathrm{IgG}$ isotypes of HA antibodies were reported in infected individuals during A (H1N1) pdm09 (Li et al. 2014). In agreement with this, currently available inactivated influenza vaccine (trivalent influenza vaccine, TIV) elicits humoral immune response predominantly against HA. However, frequent antigenic drift and an occasional shift render existing antibodies non-neutralising against the unmatched strains. This lack of cross-reactivity elicited by antibody-mediated immune response is the major limitation of currently available influenza vaccine (Soema et al. 2015). T-cell immunity is also considered vital in curbing the spread of influenza infection and minimising the period of illness (Soema et al. 2015). T-cell-mediated response in case of influenza is cross-protective and therefore, capable of imparting immunity against heterologous influenza virus 
infection. Also, it is well established that T-cell memory acquired from the previous influenza exposure prevents the subsequent hetero-subtypic influenza infections (Hayward et al. 2015; Soema et al. 2015). But the cytotoxic T-cell activity of the recall response diminishes over time in human because of the decreased number of available memory $\mathrm{T}$ cells (Deliyannis et al. 2002). To establish a swift T-cellmediated response, a pool of memory $\mathrm{T}$ cells has to be maintained continuously, thus outwitting the immediate expansion of the T-cell pool required after infection (Soema et al. 2015). Owing to the important role of $\mathrm{T}$ cell in the control of influenza infection, the concept of a T-cell-based vaccine against influenza came into existence (Atsmon et al. 2014). $\mathrm{T}$-cell recognition of antigenic epitopes depends upon the expression of peptide-bound highly polymorphic human leukocyte antigen on the surface of antigen-presenting cells (APCs) and different nucleated cells (Blum et al. 2013). Promiscuous T-cell peptides capable of binding to a large array of HLA (human leukocyte antigen) can serve as best targets for universal or influenza vaccine.

$\mathrm{HA}$ is an integral membrane protein, which forms spikes that project externally from the virus surface. It constitutes about $40 \%$ of the total mass of viral particle and plays a key role in viral adhesion and internalisation in a host cell. Various T-cell vaccines approaches based on HA peptides are under development. An oral DNA vaccine based on HA protein using attenuated Salmonella enterica sv. Typhimurium as carrier-elicited antibody, and T-cell and Th1-like cytokine responses against avian influenza virus in chickens (Jazayeri et al. 2012). Multimeric-001, which is synthetic protein construct of epitopes of HA, M1 (matrix 1 protein) and NP (nucleoprotein) in Montanide ISA 51VG adjuvant has completed phase I clinical trials (Atsmon et al. 2014). In a preclinical trial, lipopeptide preparation of HA and NP using TLR (toll-like receptor) 2 agonist Pam2Cys as an adjuvant when given with seasonal influenza vaccine induced cross-protective $\mathrm{CD} 8^{+} \mathrm{T}$-cell response in mice (Cobbin et al. 2014). There is a compelling need to identify conserved peptides capable of conferring prolonged immunity to a large portion of world population against present and future outbreaks of influenza. In our previous study, conserved peptides containing multiple $\mathrm{CD}^{+}$and $\mathrm{CD}^{+}$epitopes of $\mathrm{HA}$ protein using immunoinformatics approach were reported (Lohia and Baranwal 2014). Among these peptides, two peptides STDTVDTVLEKNVTVTHSVNL (H1) and KVNSVIEKMNTQFTAVGKEF $(\mathrm{H} 2)$ were selected for the present work which are $90.4 \%$ and $95.5 \%$ conserved, respectively, in 5673 sequences of H1N1 HA protein available from 1918 to February 2013 (Lohia and Baranwal 2014). In the IEDB database, only fragments of identified peptides such as STDTVDTVLEKNVTVTHS (Cusick et al. 2009) and SVIEKMNTQFTAVGKE (Ge et al. 2010) have been reported to elicit immune response. The immune reactivity of these two synthetic hemagglutinin peptides has been evaluated in vitro using lymphocyte proliferation by MTT \{3-(4,5-dimethylthiazolyl-2)-2,5-diphenyltetrazolium bromide $\}$ assay and interferon (IFN)- $\gamma$ ELISA (enzyme-linked immunosorbent assay). In light of the global perspective of these two peptides, peptide-HLA (human leukocyte antigen) interaction study was carried out by means of in silico molecular docking approach.

\section{Materials and methods}

\section{Synthesis of peptides}

$\mathrm{H} 1$ and $\mathrm{H} 2$ peptides were commercially synthesised by GL Biochem (Shanghai) Ltd and GenScript (USA), respectively. Peptides were dissolved in sterile MilliQ water at a concentration of $1 \mathrm{mg} / \mathrm{mL}$.

\section{Blood sampling from healthy volunteers}

Healthy human volunteers of age greater than or equal to 18 years with no active hepatitis B and C, and/or HIV infection were included in the study. Blood $(8 \mathrm{~mL})$ was drawn by the trained technicians of Lifeline blood bank, Patiala and Nitin Hospital, Patiala (India). All the volunteers gave their informed consent to donate blood for the experiments and the study was approved by institutional ethical committee.

\section{Isolation of peripheral blood mononuclear cells}

Peripheral Blood mononuclear cells (PBMC) were isolated based on the ficoll density gradient method. Whole blood was carefully layered onto the Histopaque ${ }^{\circledR}-1077$ (SigmaAldrich) and centrifuged at $400 \times g$ for $30 \mathrm{~min}$ at room temperature. After centrifugation, opaque interface (buffy coat) containing PBMC was carefully collected in a centrifuge tube. The cells were washed twice (10 min each) with phosphate buffered saline. Finally, the cell pellet was re-suspended in $1 \mathrm{~mL}$ of complete RPMI-1640 media (RPMI-1640 supplemented with $10 \%$ foetal bovine serum, $100 \mu \mathrm{g} / \mathrm{mL}$ streptomycin, $100 \mathrm{IU} / \mathrm{mL}$ penicillin and $10 \mathrm{mM}$ HEPES).

\section{Peptide-specific re-stimulation assay}

Freshly isolated healthy PBMC were cultured with individual peptides to test the immunogenic potential of peptides (Lohia and Baranwal 2017; Wullner et al. 2010). In a 24-well flatbottom cell culture plate (Thermo Scientific ${ }^{\mathrm{TM}}$ ), $2 \times 10^{6}$ cells were stimulated with each individual peptide $(25 \mu \mathrm{g} / \mathrm{mL})$ in the presence of recombinant IL (interleukin)-2 $(20 \mathrm{ng} / \mathrm{mL})$ and complete media in total volume of $2 \mathrm{~mL}$ (day 1). Unstimulated cells were supplemented with complete media and IL-2. The 
plate was incubated at $37{ }^{\circ} \mathrm{C}$ in a humidified incubator maintained at $5 \% \mathrm{CO}_{2}$ (Eppendorf New Brunswick ${ }^{\mathrm{TM}}$ Galaxy). At days 4 and 7, the culture was re-stimulated by replacing with $1 \mathrm{~mL}$ fresh complete media containing the same concentration of peptide and IL-2. On the 10th day, peptide-stimulated and -unstimulated cells were harvested and recounted for further assessing the peptide-specific IFN- $\gamma$ production and proliferative response.

\section{Measurement of Interferon $\gamma$}

To assess secretion of IFN (interferon)- $\gamma$ by peptide-stimulated $\mathrm{T}$ cells, the cells harvested on 10th day were seeded again in triplicates in 96-well plate at $1 \times 10^{5}$ cells per well in total volume of $200 \mu \mathrm{L}$ of complete media. Cells recovered from unstimulated wells were distributed in two sets of triplicates; one set stimulated with $10 \mu \mathrm{g} / \mathrm{mL}$ of concanavalin A (Con A, Sigma-Aldrich) served as positive control, whereas the other set having the unstimulated cells served as negative control. In negative control, media was supplemented with IL-2. Peptide-stimulated cells were given final stimulus with $25 \mu \mathrm{g} / \mathrm{mL}$ peptide in the presence of IL-2 $(20 \mathrm{ng} / \mathrm{mL})$. Culture supernatant was collected after 48 -h incubation and stored at $-80^{\circ} \mathrm{C}$. IFN- $\gamma$ secretion was measured by ELISA (PeproTech, USA) in 96-well ELISA plate (Nunc MaxiSorp ${ }^{\circledR}$ ) as per manufacturer's instruction. Finally, the absorbance of each well was recorded at $405 \mathrm{~nm}$, taking $630 \mathrm{~nm}$ as the reference wavelength, using a microplate reader (Tecan Austria). IFN- $\gamma$ production was expressed as fold change in cytokine release as follows:

Fold change $=$ Absorbance of the peptide stimulated cells/unstimulated cells.

\section{Lymphocyte proliferation assay}

To measure peptide-induced proliferation of PBMC, cells harvested from unstimulated and stimulated wells on the 10th day were distributed and stimulated, respectively, as discussed for IFN- $\gamma$ measurement. At the end of 6 th day, MTT $(0.5 \mathrm{mg} /$ $\mathrm{mL}$ ) was added to the culture and the culture was again incubated for $4 \mathrm{~h}$ (Lohia and Baranwal 2017). The purple-coloured formazan crystals thus formed were solubilised in $100 \mu \mathrm{L}$ DMSO (Dimethyl sulfoxide). Finally, the absorbance of each well was recorded at $570 \mathrm{~nm}$, taking $630 \mathrm{~nm}$ as the reference wavelength, using a microplate reader. Proliferation was calculated in terms of stimulation index (SI) as follows:

$\mathrm{SI}=$ Absorbance of the peptide stimulated cells/ unstimulated cells.

\section{Molecular docking of HA peptides}

The interaction of the peptides STDTVDTVLEKNVTVTHSVNL (H1) and KVNSVIEKMNTQFTAVGKEF
(H2) containing multi-epitopes with various HLA class I and II molecules was studied by means of molecular docking (Lohia and Baranwal 2015). High-resolution crystallographic structures of peptide-bound HLA complex were retrieved from the protein data bank for each class of HLA molecules (Table 1). Using the Discovery studio visualizer (v4.1), the naturally bound peptides (native peptides) were separated from the parent HLA molecules. The resultant HLA molecules were used as receptors to dock the epitopes/ peptides and the separated naturally bound peptide (used as positive controls) using the AutoDock Vina tool (Trott and Olson 2010). Based on the naturally bound peptide, the grid parameters were defined for each of the HLA molecules. The structure of the peptides comprising the epitopes was generated using the PEP-FOLD 3 server (Shen et al. 2014). The top predicted model structures of the epitopes/peptides were used for docking with class I and II HLA molecules.

\section{Statistical analysis}

Statistical analysis was performed using GraphPad prism 6 software. Data for PBMC proliferation and IFN- $\gamma$ release were analysed by one-tailed $t$ test for unpaired data. $P$ values $<0.05$ were considered statistically significant.

\section{Results}

\section{Peptides elicit IFN- $\gamma$ secretion}

Peptide-mediated activation of T cells among the population of PBMC is measured in terms of IFN- $\gamma$ production. All the seven $\mathrm{H} 1$ peptide-stimulated PBMC samples have shown significantly higher IFN- $\gamma$ production compared to the unstimulated cells (Fig. 1a). Five out of seven $\mathrm{H} 2$ peptidestimulated samples have shown significantly higher IFN- $\gamma$ production (Fig. 1b). Con A, which was used as positive control, triggered stronger IFN- $\gamma$ response in all the samples.

Table 1 HLA molecules used for molecular docking

\begin{tabular}{lllll}
\hline HLA class I & & & \multicolumn{2}{l}{ HLA class II } \\
\cline { 1 - 2 } \cline { 5 - 5 } PDB id & HLA molecule & & PDB id & HLA molecule \\
\hline 3BO8 & HLA-A1 & & 4P5M & HLA-DP2 \\
3MRK & HLA-A2 & & 3PL6 & HLA-DQ1 \\
3RL1 & HLA-A3 & & 1S9V & HLA-DQ2 \\
3WL9 & HLA-A24 & & 1UVQ & HLA-DQ0602 \\
3VCL & HLA-B7 & & 2NNA & HLA-DQ8 \\
3SPV & HLA-B8 & & 1KLU & HLA-DR1 \\
2A83 & HLA-B27 & & 1FV1 & HLA-DR2 \\
2HJL & HLA- B5703 & & 1D5M & HLA-DR4 \\
3C9N & HLA-B62 & & 3C5J & HLA-DR52c \\
\hline
\end{tabular}




\section{Peptides induce proliferative response}

To assess the proliferation of peptide-stimulated PBMC isolated from healthy donors, MTT assay was performed. Six PBMC samples stimulated with $\mathrm{H} 1$ peptide have shown proliferation, but significantly higher proliferative response was observed in four PBMC samples (Fig. 2a). Similarly, in case of H2, five PBMC samples have shown proliferation with four significantly higher proliferation (Fig. 2b). Con A-stimulated cells elicited stronger PBMC proliferation in each of the samples.

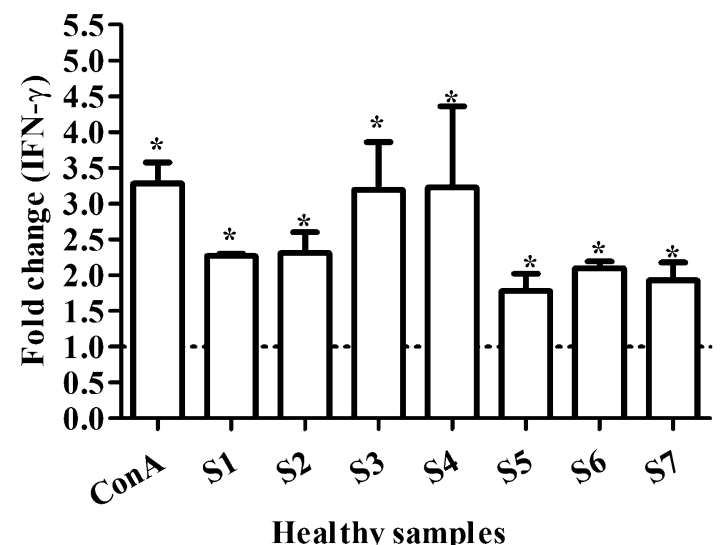

Fig. 1 Hemagglutinin peptide-induced IFN- $\gamma$ production by peripheral blood mononuclear cell a $\mathrm{H} 1$ and $\mathbf{b} \mathrm{H} 2$ measured by ELISA after day 12 ( 2 days after last peptide stimulation). Fold increase in IFN- $\gamma$ production is the ratio of absorbance of the peptide-stimulated and -unstimulated cells. Error bars represent SEM. Statistical significant

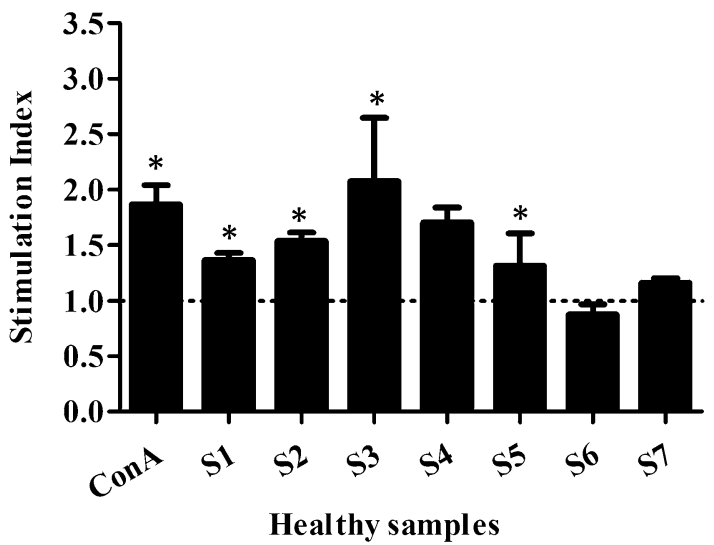

Fig. 2 Hemagglutinin peptide-induced peripheral blood mononuclear cell proliferation. a $\mathrm{H} 1$ and b $\mathrm{H} 2$ measured by MTT assay on day 16 (6 days after last peptide stimulation). Stimulation index (SI) is the ratio of average absorbance of the peptide-stimulated and -unstimulated cells. Error bars represent SEM. Statistical significant differ-

\section{HLA-peptide interaction based on molecular docking}

A key step which determines the successful induction of T-cell-mediated adaptive immune response by a peptide is the efficient binding of peptide to HLA molecule. Peptides $\mathrm{H} 1$ and $\mathrm{H} 2$ were reported to contain multiple $\mathrm{CD} 8^{+}$and $\mathrm{CD} 4^{+} \mathrm{T}$-cell epitopes, and bind to large number of alleles in the earlier study (Table 2) (Lohia and Baranwal 2014). Population coverage analysis, which estimates the expected immune response across the globe, indicated these two peptides were capable of inducing immune response in population residing in different geographical regions of the world

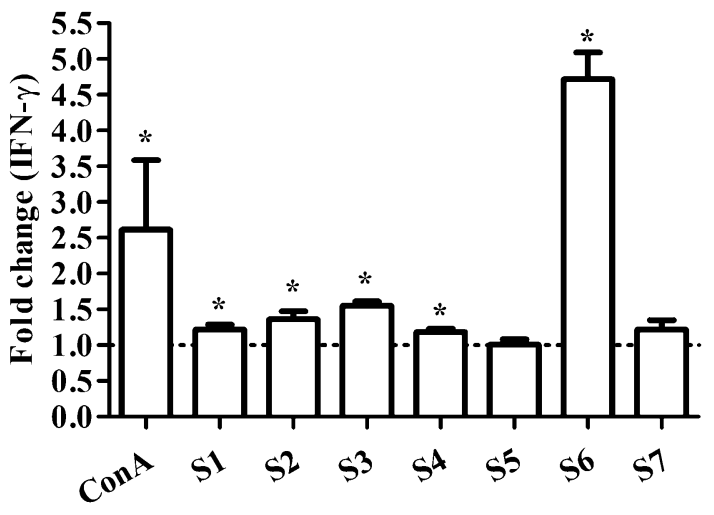

Healthy samples

differences of the mean values between peptide-unstimulated and -stimulated cells were assessed by unpaired Student's $t$ test, as indicated by $*(P<0.05)$. S1-S7 represent the different healthy samples. ConA concanavalin A

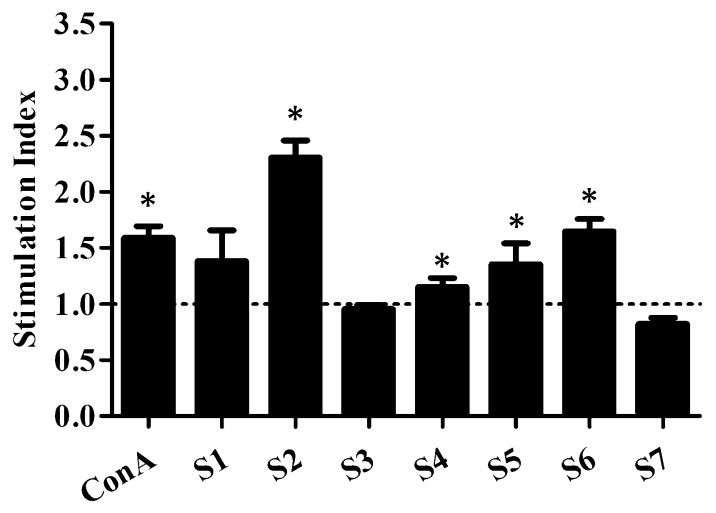

Heal thy samples

ences of the mean values between peptide-unstimulated and -stimulated cells were assessed by unpaired Student's t -test, as indicated by $*(P<0.05)$. S1-S7 represent the different healthy samples. ConA concanavalin A 
(Lohia and Baranwal 2014). Molecular docking was carried out to ascertain the binding affinity with HLA molecules. Docking study assesses the stability of protein-ligand binding interactions which is determined by change in Gibbs free energy (binding energy). The magnitude of negative binding energy is associated with stability of protein-ligand complex (Du et al. 2016). To estimate the potential of selected peptides to be presented like natural peptides by different HLA molecules, these peptides were docked with different HLA molecules and the binding energy was compared with naturally bound peptides (test control). High-resolution PDB structures of nine different HLA molecules of each class of HLA (classes I and II) which covers the various HLA alleles were selected for docking. The length of native peptides were found to be in the range of 8-11 and 9-20 amino acid residues for HLA class I and HLA class II, respectively. The binding groove of HLA class I is closed and can accommodate 8-10 residue peptides (Wieczorek et al. 2017), thus nonamer $\mathrm{CD} 8^{+} \mathrm{T}$-cell epitopes which are part of selected six peptides (Table 2) were docked with HLA class I molecules. On the other hand, HLA class II has open grooves and is capable of presenting 13-25 residue peptides; thus, $\mathrm{H} 1$ and $\mathrm{H} 2$ peptides as such were docked with class II molecules. The docked peptide-HLA configuration was compared from original PDB-obtained peptide-HLA complex by taking one example from each of HLA classes I and II to look for the structural differences and root mean square deviation (RMSD) was calculated. RMSD was observed to be 0.04 (HLA-B5703) and 0.06 (HLA-DP2) which indicate the docked peptide-HLA complex is close to native structure of peptide-HLA obtained from PDB (Supplementary fig S1). Some of peptides/epitopes could not bind to the binding groove of HLA molecules (example: STDTVDTVL and TVTHSVNLL of H1 to HLA-A2, B27 and B5703); hence, their binding energy is left over in the respective figure. In most of the cases, the binding energy of these docked epitopes/peptides was found to be comparable and close to native peptides of both the HLA classes (Figs. 3, 4). However, some peptide-HLA docked complexes were found to have better magnitude of binding energy than native peptides. Among CD8 ${ }^{+}$T-cell epitopes, QFTAVGKEF and KMNTQFTAV of $\mathrm{H} 2$ displayed better binding energy with HLA-A3 than the corresponding native peptide (Fig. 3b). $\mathrm{CD}^{+}{ }^{+} \mathrm{T}$-cell epitope enriched peptides LEKNVTVHSVNL (DQ1) of H1 and IEKMNTQFTAVG (DR1, DQ8) of H2 were found to have enhanced binding energy (Fig. 4a). The favourable binding affinity of peptides with HLA molecules demonstrated that they are presented by HLA molecules to induce peptide-specific $\mathrm{CD}^{+}$and $\mathrm{CD}^{+} \mathrm{T}$-cell response.

\section{Discussion}

Immune response to counter influenza A virus infection has been well characterised in humans (La Gruta and Turner 2014; Sun and Braciale 2013). In agreement with this, numerous peptides have been identified to elicit T-cellmediated immunity (Atsmon et al. 2014; Francis et al. 2015; Pedersen et al. 2016). Helper $\left(\mathrm{CD}^{+}\right)$and cytotoxic $\left(\mathrm{CD} 8^{+}\right)$ $\mathrm{T}$ cells were reported in viral clearance and evoking immunological response during influenza virus outbreak (Swain et al. 2004). Cells infected with virus were eliminated by cytotoxic T lymphocytes through perforin-mediated killing and contact-dependent lysis (Doherty et al. 1997). T-helper cells lead to antiviral activity by lymphokine production and help in generating B-cell responses, thus promoting the protective antibody response against the influenza (Sant et al. 2018). HA protein consists of HA1 and HA2 subunits which are linked by a disulphide bridge. The selected two highly conserved peptides, viz., STDTVDTVLEKNVTVTHSVNL (H1), is located close to the N-terminal of HA1 subunit, whereas KVNSVIEKMNTQFTAVGKEF (H2) is located in the B-loop adjacent to the N-terminal fusion peptide of HA2 subunit of hemagglutinin (Wang et al. 2015). B-loop to helix transition is the major conformational change, resulting in the release of fusion peptide at N-terminus of HA2. Further, the insertion of this fusion peptide into the endosomal membrane initiates the fusion of viral envelope with the host endosomal membrane; hence it is one of the important targets for vaccine development. These two peptides which
Table 2 HA peptides containing multiple $\mathrm{CD}^{+} \mathrm{AND} \mathrm{CD}^{+}$

T-cell epitopes

\begin{tabular}{|c|c|c|c|c|c|c|}
\hline & \multirow[t]{2}{*}{ Peptides } & \multirow[t]{2}{*}{ Position } & \multirow[t]{2}{*}{$\mathrm{CD}^{+}{ }^{+} \mathrm{T}$-cell epitope } & \multirow[t]{2}{*}{$\mathrm{CD}^{+}{ }^{+} \mathrm{T}$-cell peptide } & \multicolumn{2}{|c|}{$\begin{array}{l}\text { HLA } \\
\text { class }\end{array}$} \\
\hline & & & & & $\mathrm{I}$ & II \\
\hline $\mathrm{H} 1$ & $\begin{array}{l}\text { STDTVDTVLEKNVT- } \\
\text { VTHSVNLL }\end{array}$ & $38-59$ & $\begin{array}{l}\text { STDTVDTVL } \\
\text { DTVDTVLEK } \\
\text { TVLEKNVTV } \\
\text { TVTHSVNLL }\end{array}$ & LEKNVTVTHSVNL & 26 & 12 \\
\hline $\mathrm{H} 2$ & $\begin{array}{l}\text { KVNS- } \\
\text { VIEKMNTQFTAVG- } \\
\text { KEF }\end{array}$ & $408-427$ & $\begin{array}{l}\text { KVNSVIEKM } \\
\text { KMNTQFTAV } \\
\text { QFTAVGKEF }\end{array}$ & IEKMNTQFTAVG & 13 & 15 \\
\hline
\end{tabular}


a

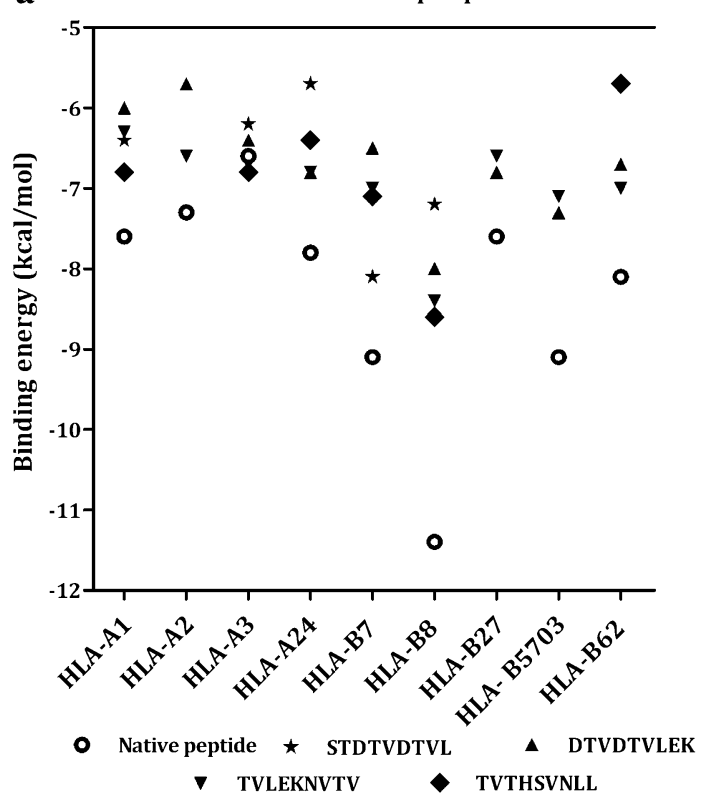

b

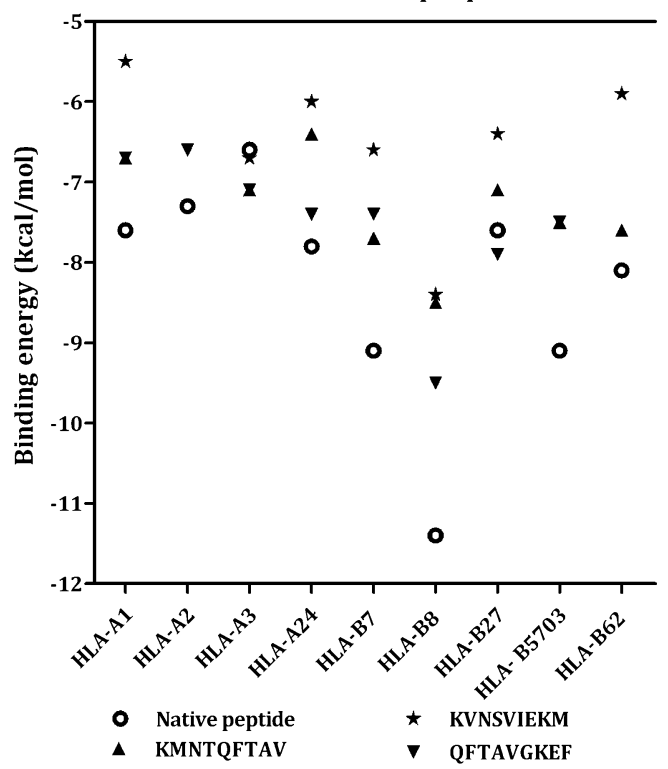

Fig. 3 Docking of $\mathrm{CD}^{+}$T-cell epitopes of HA with HLA class I molecules using AutoDock Vina. The binding energy of each HLAepitope complex a $\mathrm{H} 1$ and $\mathbf{b} \mathrm{H} 2$. Native peptides were excised from the original PDB structures of HLA class I molecule using Discovery Studio v4. 1 visualizer tool. The structures of epitopes were built using the PEP-FOLD tool. The native peptide and the $\mathrm{CD} 8^{+} \mathrm{T}$-cell epitopes of HA were docked to HLA class I molecules using Autodock vina

were predicted to contain multiple $\mathrm{CD} 4^{+}$and $\mathrm{CD} 8^{+} \mathrm{T}$-cell epitopes were found to exhibit in vitro immune response (peptide-induced IFN- $\gamma$ production and proliferation) in healthy PBMC in the current study.

The secretion of IFN- $\gamma$ along with some other cytokines is considered as the signature for antigen-induced $\mathrm{T}$-cell

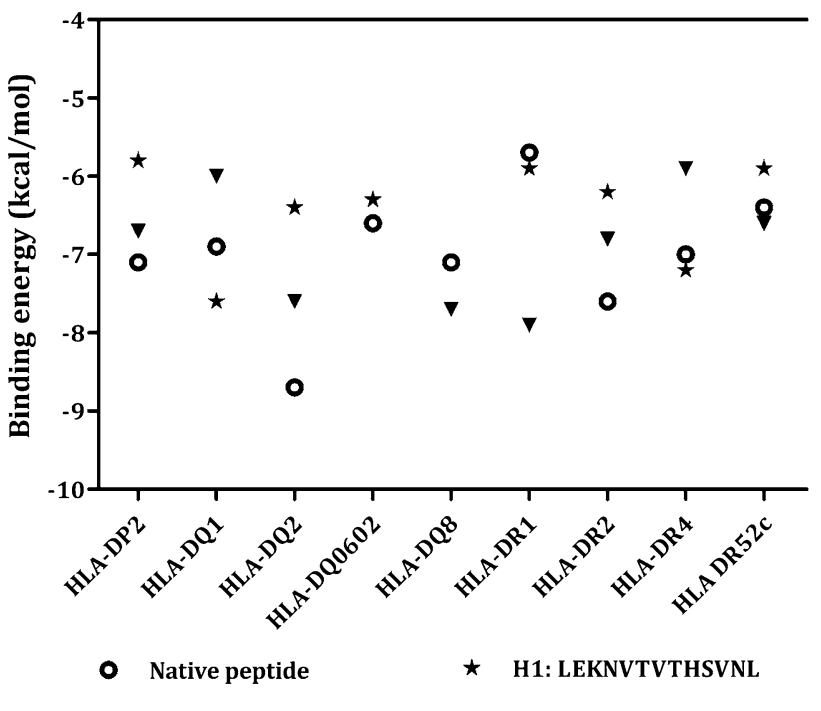

จ H2: IEKMNTQFTAVG

Fig. 4 Docking of peptides containing $\mathrm{CD}^{+}$T-cell epitopes of hemagglutinin ( $\mathrm{H} 1$ and $\mathrm{H} 2$ ) with HLA class II molecules using AutoDock vina. The binding energy for each peptide-HLA complex is obtained after docking. Native peptides were excised from the original PDB structures of HLA class II molecule using Discovery Studio v4. 1 visualizer tool. The structures of epitopes were built using the PEP-FOLD tool. The native peptide and the peptides containing multiple $\mathrm{CD}^{+}{ }^{+}$T-cell epitopes of HA were docked to HLA class II molecules using Autodock vina

proliferation and differentiation. Therefore, its accurate assessment in peptide-stimulated PBMC culture is critical in evaluating the immunogenicity of the peptide. In current scenario, three techniques most widely used for cytokine detection are flow cytometry (intracellular cytokine staining, ICS), ELISPOT and ELISA (Coughlan and Lambe 2015). Flow cytometry and ELISPOT measure the number of cytokine-positive/cytokine-secreting cells, whereas ELISA measures the total amount of cytokine secreted extracellularly. A study done in the recent past reported that there can be a lack of correlation between IFN- $\gamma$ values measured by these three techniques (Hagen et al. 2015). Higher count of cytokine-positive cells (ICS) does not necessarily indicate higher frequency of spot-forming cells (ELISPOT). Similarly, high count of spot-forming cells (SFCs) does not assure secretion of the huge amount of cytokine compared to the sample with lower SFCs (Hagen et al. 2015). ELISA has been used for detection of extracellular IFN- $\gamma$ released as a result of antigen-induced proliferation of $\mathrm{T}$ cells (Atsmon et al. 2014; Stoloff and Caparros-Wanderley 2007; Hou et al. 2012). In the present work, ELISA was employed to measure the level of released IFN- $\gamma$ as a result of peptide-stimulated cells. Significantly higher secretion of IFN- $\gamma$ level was observed in both peptide-stimulated cells for most of the healthy samples. These results indicate that the peptides are capable of inducing an immune response. 
MTT assay has been reported as a sensitive and safe non-radioactive assay for measuring PBMC proliferation by various studies (Weichert et al. 1991; Zhuge et al. 2012). Proliferation pattern obtained for the two peptides under consideration in the present study has shown a significant increase in the proliferation compared to the unstimulated cells. Out of the seven different PBMC samples, six (H1) and five $(\mathrm{H} 2)$ samples have shown proliferative response. Thus, the results indicate that both in silico-identified peptides are able to mount an immune response in terms of proliferation as well as IFN- $\gamma$ release. Although, slight variation in response of the peptides was observed in different samples due to the fact that PBMC are a heterogeneous population of cells and moreover, HLA haplotype of each individual varies because of the extensive HLA polymorphism.

As per the Influenza research database (IRD) records available on 17 April 2017, 489 immunogenic HA peptides of H1N1 hemagglutinin (from different H1N1 strains) have been reported to elicit T-cell-mediated immune response in humans. Most of these reported peptides were specific to virus strains, but current peptides used in this study were reported to be $>90 \%$ conserved across different strains of H1N1 virus (Lohia and Baranwal 2014). Moreover, these two peptides have not been exactly reported earlier for their immunogenicity as per the information available in IEDB database. Peptides VLEKNVTVTHSVNLL (Duvvuri et al. 2013) and STDTVDTVLEKNVTVTHS (Cusick et al. 2009) which are similar to peptide $\mathrm{H} 1$ have been proven to elicit $\mathrm{CD} 4^{+} \mathrm{T}$-cell-mediated immune response by means of IFN $\gamma$ release and T-cell proliferation assays. Similarly, SVIEKMNTQFTAV (Su et al. 2013) and SVIEKMNTQFTAVGKE (Ge et al. 2010) peptides similar to peptide $\mathrm{H} 2$ was also reported to elicit $\mathrm{CD}^{+}{ }^{+}$-cell-mediated immune response.

HLA genes are the most polymorphic loci among the different individuals and populations of the world. Till July of 2015, 13,412 HLA alleles have been recognised by IMGT/ HLA Database (The international ImMunoGeneTics information system) (Mack 2015). In the present study, the immunogenicity of the two peptides was evaluated in different healthy samples collected from Indian population, but it is imperative to study the immunogenicity globally. HLA molecules play a cardinal role in induction of T-cell-mediated immune response (Blum et al. 2013). Efficient binding of HLA molecules to the peptides is a critical step towards the successful induction of peptide-mediated T-cell-mediated adaptive immune response (Blum et al. 2013). Thus, analysing peptide-HLA interaction shall give an approximate idea of immunogenicity (Antunes et al. 2018).

Peptides capable of binding to an array of HLA alleles are ideal T-cell epitope-based vaccine candidates, since they are potentially immunogenic in different populations across the world. In light of this fact, nine different HLA each of classes I and II were selected for studying the peptide-HLA interaction by molecular docking. Molecular docking is identified as an expeditious, reliable and accurate technique for analysing the binding of peptide with HLA molecules (Patronov et al. 2011). In a study conducted on H5N1 nucleoprotein (NP), molecular docking was applied in combination with IFN- $\gamma$ ELISA and flow cytometry-based cell proliferation assay in in vivo models for the successful identification of epitopes (Hou et al. 2012). In another study, potential peptide vaccine candidates of Leishmania infantum were identified using structure-based molecular docking, sequence-based epitope prediction algorithm and in vitro peptide stimulation technique (Agallou et al. 2014). In the present study, nonamer $\mathrm{CD} 8^{+} \mathrm{T}$-cell epitopes and $\mathrm{CD} 4^{+}$ peptides (part of $\mathrm{H} 1$ and $\mathrm{H} 2$ peptides) were docked to HLA classes I and II, respectively, and have shown comparable binding energies with that of native bound peptides (positive controls). It is noteworthy that in some cases, experimental epitopes have displayed higher binding energy compared to the native peptides. Similarly, few epitopes/peptides-HLA molecules have shown higher binding energy values. Hence, it can be concluded that peptides exhibited overall good binding affinity with classes I and II HLA molecules which is in agreement with a previous report where these peptides were predicted to bind to a large number of HLA molecules (Lohia and Baranwal 2014). Thus, the present docking result confirms the promiscuous immunogenic nature of both the peptides and may indicate their worldwide presentation. A similar study was conducted for influenza matrix 1 (M1) peptides and Metadherin (a cell surface protein in breast tumours), taking into account HLA classes I and II molecules (Dhiman et al. 2016; Lohia and Baranwal 2015).

Various studies conducted in the past have identified highly immunogenic influenza virus peptide by means of a combined approach involving in silico screening and in vitro or in vivo validation (Duvvuri et al. 2013; Sun et al. 2010). Most remarkable example is that of the peptides of influenza identified by Stoloff and colleagues using in silico approach, which are the constituents of an influenza vaccine currently undergoing phase II clinical trial under the concept name of FluV (Stoloff and Caparros-Wanderley 2007; Pleguezuelos et al. 2012).

Vaccination is the first and best way to prevent influenza infection. Vaccines currently available against influenza are traditional formulations such as trivalent inactivated vaccine (TIV), quadrivalent inactivated vaccine (QIV) and live attenuated vaccines. These vaccines are composed of inactivated or attenuated strains of circulating influenza $\mathrm{A}$ and $B$ virus (Lee et al. 2014). Other than these, various other vaccines which have been licensed in the recent past include recombinant HA vaccine and adjuvanted or cell culturederived inactivated influenza vaccine (Krammer and Palese 2015). These strain-specific influenza virus vaccines are

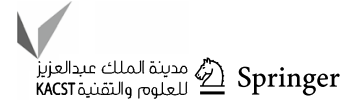


effective countermeasures against infection. But they need to be reformulated almost every year owing to antigenic drift and their efficacy varies among the individuals of different age groups. In case of a sudden outbreak, their timely and adequate availability is difficult due to the long time frame required for their production. Also, current vaccine strategies primarily bestows antibody-mediated humoral immune response which is directed against those regions of virus surface proteins (like the globular head of HA protein) which mutate rapidly due to selection pressure imposed by the host immune system. Due to this mismatch between the circulating and vaccine strain, most of the antibodies directed against HA of the vaccine strain fail to neutralise drift variant of influenza virus in circulation. Thus, virus succeeds in evading the host immune system. It is evident that vaccination modality which relies on the use of conserved T-cell epitopes existing across influenza virus subtypes to induce broad protection is being worked out.

Long synthetic immunogenic peptides containing highly conserved T-cell epitopes present a promising approach to fight influenza infection. They are devoid of any risk of reversion, genetic recombination or integration. Further, large-scale production, modification, storage and transportation (in freeze dried form) of peptides are relatively easy compared to the traditional vaccines. They are easy to synthesise with desired purity level (Purcell et al. 2007). Further, peptides are easy to be modified chemically or combined with adjuvants, carrier molecules, to enhance their delivery to immune cells. Several concepts of influenza vaccines based on peptides which elicit T-cell-mediated immune response are under clinical trial. A recombinant protein vaccine termed as Multimeric-001 vaccine composed of nine conserved linear epitopes from three different influenza proteins (HA, NP and matrix protein) is undergoing phase II trial (Atsmon et al. 2014). FP-01.1 vaccine, which is undergoing phase II clinical trials, contains six long peptides from the internal influenza protein M1, NP and polymerase basic proteins (PB1 and PB2) conjugated to fluorocarbon moiety (Francis et al. 2015). Flu-V vaccine is a mixture of four long peptides of various T-cell epitopes from M1, M2, and NP used with Montanide ISA 51VG adjuvant. This concept has also entered phase II trials (Stoloff and Caparros-Wanderley 2007; Pleguezuelos et al. 2012). All these studies support the strong candidature of immunogenic peptides containing multiple T-cell epitopes for influenza vaccine development.

To conclude, two highly conserved synthetic H1N1 hemagglutinin peptides STDTVDTVLEKNVTVTHSVNL (H1) and KVNSVIEKMNTQFTAVGKEF (H2) containing multiple overlapping $\mathrm{CD} 4^{+}$and $\mathrm{CD} 8^{+} \mathrm{T}$-cell epitopes are able to elicit immune response in terms of IFN- $\gamma$ release and proliferation. The molecular docking result suggests that they have a strong binding affinity with wide HLA molecules indicating their global representation. Hence, these peptides offer a great potential as a broadly reactive T-cell-based vaccine candidates in the fight against the epidemic as well as pandemic H1N1 influenza but not cannot prevent non-H1N1 pandemic.

Acknowledgements This work was supported by Science \& Engineering Research Board (SERB), Department of Science and Technology, Government of India (SR/FT/LS-44/2012). We would also like to acknowledge Dr. Rimpreet Singh Walia and Dr. Akshey Jain for providing us blood samples of healthy volunteers.

\section{Compliance with ethical standards}

Conflict of interest On behalf of all authors, the corresponding author states that there is no conflict of interest.

\section{References}

Agallou M, Athanasiou E, Koutsoni O, Dotsika E, Karagouni E (2014) Experimental validation of multi-epitope peptides including promising MHC class I- and class II-restricted epitopes of four known Leishmania infantum proteins. Front Immunol 5:268. https ://doi.org/10.3389/fimmu.2014.0026

Antunes DA, Devaurs D, Moll M, Lizée G, Kavraki LE (2018) General prediction of peptide-MHC binding modes using incremental docking: a proof of concept. Sci Rep 8:4327. https://doi. org/10.1038/s41598-018-22173-4

Atsmon J, Caraco Y, Ziv-Sefer S, Shaikevich D, Abramov E, Volokhov I, Bruzil S, Haima KY, Gottlieb T, Ben-Yedidia T (2014) Priming by a novel universal influenza vaccine (Multimeric001) - a gateway for improving immune response in the elderly population. Vaccine 32:5816-5823. https://doi.org/10.1016/j.vacci ne.2014.08.031

Blum JS, Wearsch PA, Cresswell P (2013) Pathways of antigen processing. Annu Rev Immunol 31:443-473. https://doi.org/10.1146/ annurev-immunol-032712-095910

Cobbin JC, Zeng W, Jackson DC, Brown LE (2014) Different arms of the adaptive immune system induced by a combination vaccine work in concert to provide enhanced clearance of influenza. PLoS One 9:e115356. https://doi.org/10.1371/journal.pone.0115356

Coughlan L, Lambe T (2015) Measuring cellular immunity to influenza: methods of detection, applications and challenges. Vaccines 3:293-319. https://doi.org/10.3390/vaccines3020293

Cusick MF, Wang S, Eckels DD (2009) In vitro responses to avian influenza H5 by human CD4 T cells. J Immunol 183:6432-6441. https://doi.org/10.4049/jimmunol.0901617

Deliyannis G, Jackson DC, Ede NJ, Zeng W, Hourdakis I, Sakabetis E, Brown LE (2002) Induction of long-term memory CD8 (+) $\mathrm{T}$ cells for recall of viral clearing responses against influenza virus. J Virol 76:4212-4221. https://doi.org/10.1128/ JVI.76.9.4212-4221.2002

Dhiman G, Lohia N, Jain S, Baranwal M (2016) Metadherin peptides containing $\mathrm{CD} 4(+)$ and $\mathrm{CD} 8(+) \mathrm{T}$ cell epitopes as a therapeutic vaccine candidate against cancer. Microbiol Immunol 60:646652. https://doi.org/10.1111/1348-0421.12436

Doherty PC, Topham DJ, Tripp RA, Cardin RD, Brooks JW, Stevenson PG (1997) Effector CD4 + and CD8 + T-cell mechanisms in the control of respiratory virus infections. Immunol Rev 159:105117. https://doi.org/10.1111/j.1600-065X.1997.tb01010.X

Du X, Li Y, Xia Y-L, Ai S-M, Liang J, Sang P, Ji X-L, Liu S-Q (2016) Insights into protein-ligand interactions: mechanisms, models, 
and methods. Int J Mol Sci 17:144. https://doi.org/10.3390/ijms1 7020144

Duvvuri VR, Duvvuri B, Jamnik V, Gubbay JB, Wu J, Wu GE (2013) $T$ cell memory to evolutionarily conserved and shared hemagglutinin epitopes of H1N1 viruses: a pilot scale study. BMC Infect Dis 13:204. https://doi.org/10.1186/1471-2334-13-204

Francis JN, Bunce CJ, Horlock C, Watson JM, Warrington SJ, Georges B, Brown CB (2015) A novel peptide-based pan-influenza A vaccine: a double blind, randomised clinical trial of immunogenicity and safety. Vaccine 33:396-402. https://doi.org/10.1016/j.vacci ne.2014.06.006

Galiano M, Agapow P-M, Thompson C, Platt S, Underwood A, Ellis J, Myers R, Green J, Zambon M (2011) Evolutionary pathways of the pandemic influenza A (H1N1) 2009 in the UK. PloS one 6:e23779. https://doi.org/10.1371/journal.pone.0023779

Ge X, Tan V, Bollyky PL, Standifer NE, James EA, Kwok WW (2010) Assessment of seasonal influenza A virus-specific CD4 T-cell responses to 2009 pandemic H1N1 swine-origin influenza A virus. J Virol 84:3312-3319. https://doi.org/10.1128/JVI.02226 $-09$

Hagen J, Zimmerman R, Goetz C, Bonnevier J, Houchins JP, Reagan K, Kalyuzhny AE (2015) Comparative multi-donor study of IFN $\gamma$ secretion and expression by human PBMCs using ELISPOT sideby-side with ELISA and flow cytometry assays. Cells 4:84-95. https://doi.org/10.3390/cells4010084

Hayward AC, Wang L, Goonetilleke N, Fragaszy EB, Bermingham A, Copas A, Dukes O, Millett ER, Nazareth I, Nguyen-Van-Tam JS, Watson JM, Zambon M, Flu Watch Group, Johnson AM, McMichael AJ (2015) Natural T cell-mediated protection against seasonal and pandemic influenza. Results of the flu watch cohort study. Am J Respir Crit Care Med 191:1422-1431. https://doi. org/10.1164/rccm.201411-1988OC

Hou Y, Guo Y, Wu C, Shen N, Jiang Y, Wang J (2012) Prediction and identification of $\mathrm{T}$ cell epitopes in the $\mathrm{H} 5 \mathrm{~N} 1$ influenza virus nucleoprotein in chicken. PLoS One 7(6):e39344. https://doi. org/10.1371/journal.pone.0039344

Jazayeri SD, Ideris A, Zakaria Z, Yeap SK, Omar AR (2012) Improved immune responses against avian influenza virus following oral vaccination of chickens with HA DNA vaccine using attenuated Salmonella typhimurium as carrier. Comp Immunol Microbiol Infect Dis 35:417-427. https://doi.org/10.1016/j.cimid .2012.03.007

Krammer F, Palese P (2015) Advances in the development of influenza virus vaccines. Nat Rev Drug Discov 14:167-182. https:// doi.org/10.1038/nrd4529

La Gruta NL, Turner SJ (2014) T cell mediated immunity to influenza: mechanisms of viral control. Trends Immunol 35:396-402. https ://doi.org/10.1016/j.it.2014.06.004

Lee YT, Kim KH, Ko EJ, Lee YN, Kim MC, Kwon YM, Tang Y, Cho MK, Lee YJ, Kang SM (2014) New vaccines against influenza virus. Clin Exp Vaccine Res 3:12-28. https://doi.org/10.7774/ cevr.2014.3.1.12

Li ZN, Lin SC, Carney PJ, Li J, Liu F, Lu X, Liu M, Stevens J, Levine M, Katz JM, Hancock K (2014) IgM, IgG, and IgA Antibody Responses to Influenza A(H1N1)pdm09 Hemagglutinin in Infected Persons during the First Wave of the 2009 Pandemic in the United States. Clin Vaccine Immunol 21:1054-1060. https:// doi.org/10.1128/CVI.00129-14

Lohia N, Baranwal M (2014) Conserved peptides containing overlapping $\mathrm{CD}^{+}$and $\mathrm{CD}^{+}$T-cell epitopes in the $\mathrm{H} 1 \mathrm{~N} 1$ influenza virus: an immunoinformatics approach. Viral Immunol 27:225-234. https://doi.org/10.1089/vim.2013.0135

Lohia N, Baranwal M (2015) Identification of conserved peptides comprising multiple $\mathrm{T}$ cell epitopes of matrix 1 protein in $\mathrm{H} 1 \mathrm{~N} 1$ influenza virus. Viral Immunol 28:570-579. https://doi.org/10.1089/ vim.2015.0060
Lohia N, Baranwal M (2017) Immune responses to highly conserved influenza A virus matrix 1 peptides. Microbiol Immunol 61(6):225-231. https://doi.org/10.1111/1348-0421.12485

Mack SJ (2015) A gene feature enumeration approach for describing HLA allele polymorphism. Hum Immunol 76:975-981. https:// doi.org/10.1016/j.humimm.2015.09.016

Patronov A, Dimitrov I, Flower DR, Doytchinova I (2011) Peptide binding prediction for the human class II MHC allele HLA-DP2: a molecular docking approach. BMC Struct Biol 11:1-10. https ://doi.org/10.1186/1472-6807-11-32

Pedersen SR, Christensen JP, Buus S, Rasmussen M, Korsholm KS, Nielsen M, Claesson MH (2016) Immunogenicity of HLA class I and II double restricted influenza A-derived peptides. PLoS One 11:e0145629. https://doi.org/10.1371/journal.pone.0145629

Pleguezuelos O, Robinson S, Stoloff GA, Caparros-Wanderley W (2012) Synthetic Influenza vaccine (FLU-v) stimulates cell mediated immunity in a double-blind, randomised, placebo-controlled phase I trial. Vaccine 30:4655-4660. https://doi.org/10.1016/j. vaccine. 2012.04.089

Purcell AW, McCluskey J, Rossjohn J (2007) More than one reason to rethink the use of peptides in vaccine design. Nat Rev Drug Discov 6:404-414. https://doi.org/10.1038/nrd2224

Sant AJ, DiPiazza AT, Nayak JL, Rattan A, Richards KA (2018) CD4 $\mathrm{T}$ cells in protection from influenza virus: viral antigen specificity and functional potential. Immunol Rev 284:91-105. https://doi. org/10.1111/imr.12662

Shen Y, Maupetit J, Derreumaux P, Tuffery P (2014) Improved PEPFOLD approach for peptide and miniprotein structure prediction. J Chem Theory Comput 10:4745-4758. https://doi.org/10.1021/ ct500592m

Soema PC, van Riet E, Kersten G, Amorij JP (2015) Development of cross-protective influenza a vaccines based on cellular responses. Front Immunol 6:237. https://doi.org/10.3389/fimmu.2015.00237

Stoloff GA, Caparros-Wanderley W (2007) Synthetic multi-epitope peptides identified in silico induce protective immunity against multiple influenza serotypes. Eur J Immunol 37:2441-2449. https ://doi.org/10.1002/eji.200737254

Su LF, Kidd BA, Han A, Kotzin JJ, Davis MM (2013) Virus-specific CD4(+) memory-phenotype T cells are abundant in unexposed adults. Immunity 38:373-383. https://doi.org/10.1016/j.immun i.2012.10.021

Sun J, Braciale TJ (2013) Role of T cell immunity in recovery from influenza virus infection. Curr Opin Virol 3:425-429. https://doi. org/10.1016/j.coviro.2013.05.001

Sun Y, Liu J, Yang M, Gao F, Zhou J, Kitamura Y, Gao B, Tien P, Shu Y, Iwamoto A, Chen Z, Gao GF (2010) Identification and structural definition of H5-specific CTL epitopes restricted by HLAA*0201 derived from the H5N1 subtype of influenza A viruses. J Gen Virol 91:919-930. https://doi.org/10.1099/vir.0.016766-0

Swain SL, Dutton RW, Woodland DL (2004) T cell responses to influenza virus infection: effector and memory cells. Viral Immunol 17:197-209. https://doi.org/10.1089/0882824041310577

Trott O, Olson AJ (2010) AutoDock vina: improving the speed and accuracy of docking with a new scoring function, efficient optimization, and multithreading. J Comput Chem 31:455-461. https ://doi.org/10.1002/jcc.21334

Wang W, DeFeo CJ, Alvarado E, Vassell R, Weiss CD (2015) Intermonomer interactions in hemagglutinin subunits HA1 and HA2 affecting hemagglutinin stability and influenza virus infectivity. J Virol JVI. https://doi.org/10.1128/JVI.00939-15

Weichert H, Blechschmidt I, Schroder S, Ambrosius H (1991) The MTT-assay as a rapid test for cell proliferation and cell killing: application to human peripheral blood lymphocytes (PBL). Allerg Immunol (Leipz) 37:139-144

WHO (2014) Influenza (Seasonal) fact sheet $\mathrm{N}^{\circ} 211$. http://www.who. int/mediacentre/factsheets/fs211/en/. Assessed 13 Feb 2016

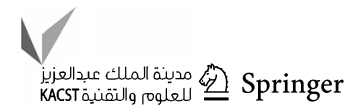


Wieczorek M, Abualrous ET, Sticht J, Álvaro-Benito M, Stolzenberg S, Noé F, Freund C (2017) Major histocompatibility complex (MHC) class I and MHC class II proteins: conformational plasticity in antigen presentation. Front Immunol 8:292. https://doi. org/10.3389/fimmu.2017.00292

Wullner D, Zhou L, Bramhall E, Kuck A, Goletz TJ, Swanson S, Chirmule N, Jawa V (2010) Considerations for optimization and validation of an in vitro PBMC derived $\mathrm{T}$ cell assay for immunogenicity prediction of biotherapeutics. Clin Immunol 137:5-14. https://doi.org/10.1016/j.clim.2010.06.018

Zhuge ZY, Zhu YH, Liu PQ, Yan XD, Yue Y, Weng XG, Zhang R, Wang JF (2012) Effects of astragalus polysaccharide on immune responses of porcine PBMC stimulated with PRRSV or CSFV. PLoS One 7:e29320. https://doi.org/10.1371/journal.pone.00293 20 